This is the final peer-reviewed accepted manuscript of:

Nunziatina Russo, Alessandra Pino, Attilio Toscano, Giuseppe L.Cirelli, Cinzia Caggia, Stefania Arioli, Cinzia L. Randazzo "Occurrence, diversity, and persistence of antibiotic resistant enterococci in full-scale constructed wetlands treating urban wastewater in Sicily"

which has been published in final form in Bioresource Technology, Volume 274, February 2019, Pages 468-478

The final published version is available online at:

https://doi.org/10.1016/i.biortech.2018.12.017

(C) 2019 Elsevier. This manuscript version is made available under the Creative Commons Attribution-NonCommercial-NoDerivs (CC BY-NC-ND) 4.0 International License (http://creativecommons.org/licenses/by-nc-nd/4.0/) 


\title{
Occurrence, diversity, and persistence of antibiotic resistant enterococci in full-scale constructed wetlands treating urban wastewater in Sicily
}

\author{
Nunziatina Russo ${ }^{\mathrm{a}}$, Alessandra Pino ${ }^{\mathrm{a}}$, Attilio Toscano ${ }^{\mathrm{b}}$, Giuseppe L. Cirelli ${ }^{\mathrm{a}}$, Cinzia Caggia ${ }^{\mathrm{a}, *}$, \\ Stefania Arioli ${ }^{\mathrm{c}}$, Cinzia L. Randazzo ${ }^{\mathrm{a}}$ \\ ${ }^{a}$ Department of Agriculture, Food and Environment (Di3A), University of Catania, Via Santa Sofia 100, Catania 95123, Italy \\ ${ }^{\mathrm{b}}$ Department of Agricultural and Food Sciences (DISTAL), Alma Mater Studiorum - University of Bologna, Viale Giuseppe Fanin 50, Bologna 40127, Italy \\ ${ }^{\mathrm{c}}$ Department of Food Environmental and Nutritional Science (DeFENS), University of Milan, Italy
}

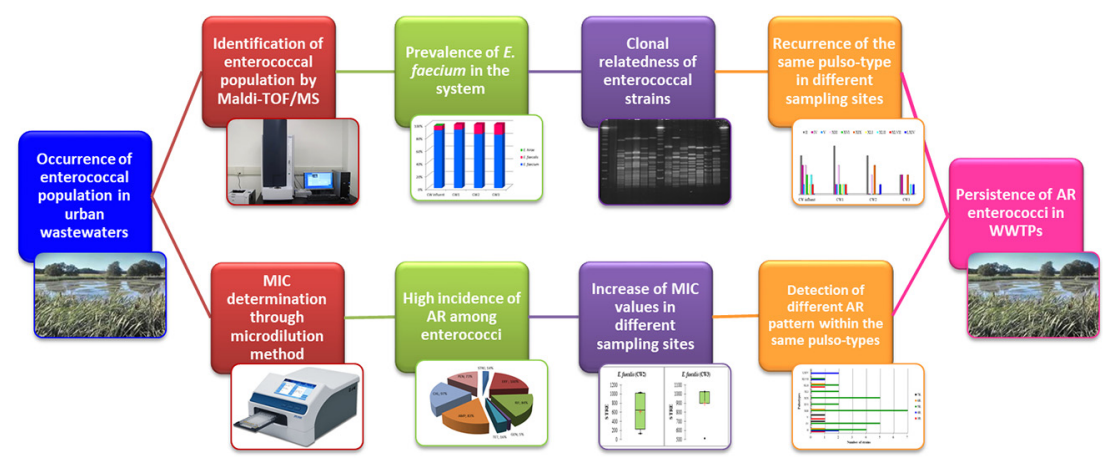

A B S T R A C T

\begin{abstract}
Enterococci isolated from different sites of an urban wastewater treatment plant (consisting of three horizontal subsurface flow constructed wetlands) were investigated. One-hundred-thirty isolates were identified at species level and tested for resistance to eleven antibiotics, by microdilution method, and their clonal relatedness was established by SmaI-PFGE analysis. Results highlighted the persistence of enterococcal population in all effluents and the dominance of $E$. faecium species. A high incidence of antibiotic resistance against erythromycin, chloramphenicol, rifampicin and ampicillin was observed, with 120 strains (93\%) showing a multi-drug-resistance. Numerous pulso-types with a unique pattern were detected indicating a high diversity within enterococcal population. The recurrence of some pulso-types in different effluents was disclosed and, within the same pulso-types, different resistance patterns were observed. Comparing the MIC values of strains from inlet and outlet, different trends were observed, highlighting a certain variability among constructed wetlands in affecting the antibiotic resistance among enterococcal population.
\end{abstract}

Keywords:

Urban wastewater treatment plant

Constructed wetland

Antibiotic resistance

Enterococcus faecium

Enterococcus faecalis

Clones

\section{Background}

Antimicrobial resistance (AR) is a complex phenomenon and represents a public concern, compromising the ability to cure a wide range of infectious diseases (Martinez and Baquero, 2014; Hay et al., 2018; WHO, 2017). The overuse of antimicrobials may have greatly

\footnotetext{
* Corresponding author.

E-mail address: ccaggia@unict.it (C. Caggia).
} 
accelerated the spread of different resistance mechanisms (Hay et al., 2018). Large amounts of antimicrobial compounds together with resistant bacteria can reach wastewater treatment plants (WWTPs). The entrance of antibiotics into biological WWTPs, mainly at sub-therapeutic concentrations can reduce their efficiency and promote the selection of AR among bacteria population (Kim et al., 2007). Enterococci are members of intestinal microbiota of a wide variety of hosts and are able to survive to harsh conditions. Their presence in WWTPs could be detected at high densities (Byappanahalli et al., 2012). Enterococci are intrinsically resistant to a plethora of antibiotics and for the high frequency of multiple antibiotic resistance they have emerged as opportunistic pathogens (Gao et al., 2018). Furthermore their ability to acquire different adaptive traits and to transfer resistance to pathogenic species, makes this group a relevant healthcare problem (Oravcová et al., 2017; Werner et al., 2013). Recently the World Health Organization (WHO) has considered the vancomycin resistant Enterococcus faecium a high priority pathogen (WHO, 2017). WWTPs, for their intrinsic parameters, such as $\mathrm{pH}$, temperature, high nutrient concentration, presence of antibiotics (and/or their metabolites) and for supporting a close contact between bacteria, provide an ideal ecosystem to promote selection of resistant strains and transferring of resistance genes (Rodriguez-Mozaz et al., 2015). Among the different types of WWTPs, constructed wetlands (CWs) represent a natural treatment system widely used thanks to their capability to efficiently treat wastewater from several sources (i.e., small/medium communities, agricultural drainage, agro-industries, road runoff, landfill leachate) with low energy, easier maintenance and low operational costs (Lavrnić et al., 2018). Furthermore, CWs can be used as treatment systems for wastewater reuse in agriculture (Barbagallo et al., 2011), also combined with other technologies.

Even if numerous studies have been conducted on hospital wastewater treatment systems, to the best of our knowledge, this is the first study carried out on persistence of antibiotic resistant enterococci in a natural urban wastewater treatment plant (CWs) in Sicily.

Therefore, the current study aims to evaluate: (i) the phenotypic antibiotic resistance of enterococcal isolates; (ii) the occurrence and the persistence of antibiotic resistant enterococci both in influent and in effluents of three subsurface flow CW treatment systems; (iii) the clonal relatedness among isolated strains.

\section{Materials and methods}

\subsection{Experimental plant}

The present study was carried out in three horizontal subsurface flow CWs, namely CW1, CW2 and CW3, which receive the secondary effluents of the urban WWTP from San Michele di Ganzaria $\left(37^{\circ} 17^{\prime} 0^{\prime \prime} \mathrm{N}\right.$ and $14^{\circ} 26^{\prime} 0^{\prime \prime} \mathrm{E}$ ). San Michele di Ganzaria is a small community (about 3200 inhabitants, in 2016 as reported in http://www.comuni-italiani. it/087/011/statistiche/popolazione.html) of Eastern Sicily, located in Csa Hot-summer Mediterranean climate, according to Köppen classification (also known as a Mediterranean climate), with a mean annual temperature of $18{ }^{\circ} \mathrm{C}$ and mean annual rainfall of $500 \mathrm{~mm}$. Basically two seasons can be distinguished: from April to September (summer, dry and hot, with mean temperatures of $20^{\circ} \mathrm{C}$ and mean rainfall of $20 \mathrm{~mm}$ / month), and from October to March (winter, wet and cool, with mean temperatures of $11^{\circ} \mathrm{C}$ and mean rainfall of $91 \mathrm{~mm} / \mathrm{month}$ ).

CW1, CW2, and CW3 are part of the largest natural WWTP of South Italy that includes four CWs operating in parallel, followed by three wastewater storage reservoirs, realized for tertiary treatment of municipal wastewater aimed at agricultural reuse (Cirelli et al., 2007). The main design and operation characteristics of wetland beds are reported in Table 1.

\subsection{Sampling sites}

The study was performed between April and September 2016. Influent and treated wastewater samples were collected in April, May, June, July and September 2016 at: (1) Influent (i.e., following WWTP); (2) CW1 outlet effluent; (3) CW2 outlet effluent; and (4) CW3 outlet effluent. The CWs were used for tertiary treatment for wastewater reuse in agriculture. Samples were collected in sterile bottles and transported in refrigerated conditions to the laboratory of Microbiology at the Department of Agriculture, Food and Environment, University of Catania, and analyzed within $24 \mathrm{~h}$ from sampling.

\subsection{Enumeration of enterococci}

Influent, after decanting, and effluent samples were subjected to microbiological analyses by membrane filtration method, according to Standard Methods for the Examination of Water and Wastewater (APHA, 2006). Briefly, samples were diluted in a sterile saline solution and $100 \mathrm{~mL}$ of each dilution were filtered through a $0.45 \mu \mathrm{m}$ pore-size sterilized membrane filters (Microfil V, Merk Millipore, Italy), according to ISO 9001:2008 procedures. Each membrane filter was placed on Slanetz Bartley Agar (SBA, BIOLIFE, Italy) for enumeration of Enterococcus spp. The plates were incubated at $37^{\circ} \mathrm{C}$ for $48 \mathrm{~h}$, under aerobic conditions. Colonies grown on filters were counted and the enterococcal abundance was reported as $\log _{10}$ colony-forming units (CFU/100 mL of water). The analysis was performed in duplicate.

\subsection{Isolation and phenotypic characterization of enterococci}

Colonies from SBA plates were randomly isolated and analyzed for colony characteristics and cell morphology. Overall, 130 isolates were collected and tested for Gram staining, catalase reaction, growth at $45^{\circ} \mathrm{C}$ and $10{ }^{\circ} \mathrm{C}$, growth in presence of $6.5 \%(\mathrm{w} / \mathrm{v})$ of $\mathrm{NaCl}$ and at $\mathrm{pH}$ 9.6, and growth on on Kanamycin Aesculin Azide agar (Liofilchem). Presumptive enterococci were streaked three times and the pure cultures were stored at $-80^{\circ} \mathrm{C}$ in Brain Heart Infusion (BHI, Oxoid) broth supplemented with $20 \%$ (v/v) glycerol for the further analyses. Overall, 130 Gram-positive, catalase negative cocci in pairs or as short chains were considered as belonging to Enterococcus genus.

\subsection{Maldi-TOF/MS analysis}

The 130 presumptive enterococci were subjected to species identification by matrix-assisted laser desorption/ionisation time-of-flight mass spectrometry MALDI-TOF/MS (Bruker Daltonics, Germany). Measurements were performed with a Microflex LT mass spectrometer (Bruker Daltonik, Germany) using FlexControl software (version 3.0). The spectra were imported into the integrated MALDI Biotyper software (version 3.0) and analyzed by standard pattern matching with default settings. The strains were treated as previously reported (Doan et al., 2012). The spectrum of each isolate was compared with those present in the database and identification was provided with a score of reliability. Standard Bruker interpretative criteria were applied; scores $\geq 2.0$ were accepted for species assignment and scores $\geq 1.7$ but $\leq 2.0$ for genus identification.

\subsection{Antimicrobial susceptibility testing}

Enterococcal strains were characterized for their susceptibility to a panel of eleven antibiotics, according to Russo and co-workers (2018). In details, the Minimum Inhibitory Concentration (MIC) values were evaluated for each antibiotic within different range, as follow: tetracycline (from 0.5 to $16-\mu \mathrm{g} / \mathrm{mL}$ ), erythromycin (from 1 to $32 \mu \mathrm{g} / \mathrm{mL}$ ), streptomycin (from 32 to $1024 \mu \mathrm{g} / \mathrm{mL}$ ), gentamycin (from 8 to $256 \mu \mathrm{g}$ / $\mathrm{mL}$ ), ampicillin (from 1 to $32 \mu \mathrm{g} / \mathrm{mL}$ ), rifampicin (from 2 to $64 \mu \mathrm{g} / \mathrm{mL}$ ), penicillin $\mathrm{G}$ (from 0.5 to $16 \mu \mathrm{g} / \mathrm{mL}$ ), sulfamethoxazole (from 128 to 
Table 1

Constructed wetland characteristics.

\begin{tabular}{|c|c|c|c|c|c|c|c|c|}
\hline \multirow[t]{2}{*}{ Constructed wetlands } & \multirow[t]{2}{*}{ Operation time (year) } & \multirow[t]{2}{*}{ Flow rate $\left(\mathrm{m}^{3} /\right.$ day $)$} & \multirow[t]{2}{*}{ Area $\left(\mathrm{m}^{2}\right)$} & \multicolumn{4}{|l|}{ Gravel } & \multirow[t]{2}{*}{ Macrophytes planted } \\
\hline & & & & Type & Size $(\mathrm{mm})$ & Nominal porosity & Depth (m) & \\
\hline CW1 & 12 & 240 & 2000 & volcanic & $8-15$ & 0.47 & 0.6 & Phragmites australis \\
\hline CW2 & 6 & 240 & 2000 & & & & & \\
\hline CW3 & 6 & 125 & 1200 & & & & & Typha latifolia \\
\hline
\end{tabular}

\section{Table 2}

Enterococcal cell density in WWTP. Data are reported as mean values (expressed as $\log _{10} \mathrm{CFU} / 100 \mathrm{~mL}$ ) and Standard Deviation of two independent samples.

\begin{tabular}{|c|c|c|c|c|}
\hline \multirow[t]{2}{*}{ Sampling month } & \multirow[t]{2}{*}{ Influent } & \multicolumn{3}{|l|}{ Effluents } \\
\hline & & CW1 & CW2 & CW3 \\
\hline April & $4.50^{\mathrm{a}} \pm 0.41$ & $3.88^{\mathrm{a}} \pm 0.07$ & $3.89^{\mathrm{a}} \pm 0.17$ & $3.47^{\mathrm{a}} \pm 0.20$ \\
\hline May & $3.37^{\mathrm{a}} \pm 0.55$ & $2.77^{\mathrm{a}} \pm 0.11$ & $4.12^{\mathrm{b}} \pm 0.18$ & $3.60^{\mathrm{a}} \pm 0.29$ \\
\hline June & $4.46^{\mathrm{b}} \pm 0.37$ & $3.23^{\mathrm{a}} \pm 0.31$ & $2.44^{\mathrm{a}} \pm 0.36$ & $3.17^{\mathrm{a}} \pm 0.14$ \\
\hline July & $2.51^{b} \pm 0.32$ & $1.70^{\mathrm{a}} \pm 0.06$ & $1.08^{\mathrm{a}} \pm 0.06$ & $1.98^{\mathrm{a}} \pm 0.02$ \\
\hline September & $5.38^{\mathrm{b}} \pm 0.01$ & $3.60^{\mathrm{a}} \pm 0.48$ & $2.70^{\mathrm{a}} \pm 0.36$ & $3.87^{c} \pm 0.12$ \\
\hline Mean value & $4.04 \pm 1.12$ & $3.03 \pm 0.85$ & $2.85 \pm 1.23$ & $3.22 \pm 0.73$ \\
\hline
\end{tabular}

${ }^{\mathrm{abc}}$ for each sampling point, in the same row followed by different lower case letters are statistically different $(\mathrm{P} \leq 0.05)$

$4096 \mu \mathrm{g} / \mathrm{mL}$ ), chloramphenicol (from 2 to $64 \mu \mathrm{g} / \mathrm{mL}$ ), vancomycin (from 1 to $32 \mu \mathrm{g} / \mathrm{mL}$ ) and kanamycin (from 128 to $4096 \mu \mathrm{g} / \mathrm{mL}$ ). All antibiotics were purchased from Sigma-Aldrich (St. Louis, MO, USA). The MICs were determined by micro-dilution method, using MuellerHinton broth (Liofilchem) and MIC tests were performed in a 384-well plates, filled with an automatic liquid handling system (EpMotion, Eppendorf, Italy) to a final volume of $80 \mu \mathrm{L}$. The bacteria were incubated in absence (control) and in presence of each antibiotic at six different concentrations. E. faecalis ATCC 29212 was used as reference strain. Each strain was exposed, in duplicate, to each antimicrobial concentration, at a final inoculum density of 0.5 McFarland, starting from overnight cultures. The bacterial cell concentration was determined by flow cytometry (BD Accuri ${ }^{\mathrm{TM}}$ C6 Plus Flow Cytometer, BD Biosciences, Milan, Italy). The 384 -well plates were incubated at $37^{\circ} \mathrm{C}$ for $24 \mathrm{~h}$ and the cell density evaluated by OD measuring, using a spectrophotometer (MicroWave RS2, Biotek, USA) and the Gene5 software (Biotek, USA). The MIC was determined as the lowest antimicrobial concentration that inhibited bacterial growth and the results were interpreted according to CLSI (2016) and EUCAST (2018)-approved clinical breakpoint and epidemiological cut-off values, with exception of sulfamethoxazole and kanamycin, for which no breakpoint and/or epidemiological cut-off are available (CLSI, 2016; EUCAST, 2018). Enterococci resistant to at least one agent of three or more antimicrobial classes were considered as multidrug resistant (MDR).

\subsection{Clonal relatedness}

The clonal relationship among the 130 isolates was revealed by comparison of SmaI digested DNA profiles, using PFGE analysis. Highmolecular-weight DNA was isolated from $1 \mathrm{~mL}$ of an overnight culture, as previously reported (Novais et al., 2004; Tenover et al., 1995). The digested plugs were subjected to electrophoresis, using the CHEF-DR III system (Bio-Rad Laboratories, Hercules, CA, USA), in a 1.2\% agarose gels at $6 \mathrm{~V} / \mathrm{cm}$, with linear switching interval ramps from $35 \mathrm{~s}$ to $25 \mathrm{~s}$ for $25 \mathrm{~h}$ at $14^{\circ} \mathrm{C}$ for the first block. Lambda ladder (New England BioLabs, Beverly, MA, UK) was run as molecular weight marker. After staining with gel red (Biotium), DNA bands were visualized by UV. The images acquisition was performed by using ChemiDoc $^{\mathrm{TM}}$ MP Imaging System (Bio-Rad Laboratories Inc. Hercules, California, USA). The PFGE profiles were converted to TIFF files and subjected to cluster analysis, using BioNumerics v. 7.5 software (Applied Maths, Sint-Martens-Latem, Belgium). PFGE profiles were interpreted according to criteria of Tenover et al. (1995). PFGE band patterns were generated by BioNumerics v. 7.5 software (Applied Maths, Sint-Martens-Latem, Belgium) with tolerance position of $1 \%$. Clustering was based on the unweighted pair group method with arithmetic averages (UPGMA). The Dice correlation coefficient was used to detect the similarities of banding patterns.

\subsection{Data processing}

The multiple antibiotic resistance (MAR) index was computed for both each strain and each sampling site, according to Krumperman (1983). The MAR index referred to a single strain was calculated as $=a / b$, where $a$ represents the number of antibiotics to which isolate resulted resistant, and $b$ represents the number of antibiotics to which isolate was exposed. MAR index referred to each sampling site was calculated as $=c /(\mathrm{n} \cdot b)$, where $c$ represents the total number of resistance scores; $\mathrm{n}=$ number of isolates from the site; $b$ number of tested antibiotics.

\subsection{Statistical analysis}

All experiments were performed in duplicate and results were reported as average values, provided with Standard Deviation. All microbiological statistical analyses were performed using XLSTAT statistical software. The statistical significance between enterococcal density in samples before and after each CW unit was evaluated by one-way analyses of variance (ANOVA). Results were considered significant at the $5 \%$ level $(P=0.05)$. In addition, the XLSTAT statistical software was used to correlate antibiotic resistance patterns within enterococcal population and also to correlate detected MIC values with enterococcal species.

\section{Results and discussion}

\subsection{Microbiological analyses}

The occurrence of AR resistant enterococci in three CWs effluents receiving the same influent were evaluated and results of microbiological mean values, at the different sampling points and sampling times are shown in Table 2. Considering the different sampling times, the mean $\log _{10}$ values of enterococci in inlet samples (influent) was 4.04, with the highest enterococcal density in September (about $5.4 \mathrm{log}$ $\mathrm{CFU} / 100 \mathrm{~mL}$ ) and the lowest in July (2.5 log CFU/100 mL). In CW1, CW2, and CW3 effluents the mean enterococcal load was 3.03, 2.85 and 3.22, respectively. An increase of enterococci counts was observed, both in CW2 and CW3 effluents sampled in May. The observed slight decrease in all effluents is in agreement with previous studies (Graves and Weaver, 2010; Martins da Costa et al., 2006), confirming that conventional wastewater treatments are not able to efficiently remove these microorganisms. Furthermore different persistence rates (calculated as percentage ratio between inlet and outlet loads) were detected in the three effluents, with values ranging from $86 \%$ to $67 \%$ in the CW1; from $86 \%$ to $50 \%$ in CW2 and; from $79 \%$ to $72 \%$ in CW3 effluents (data not shown). Several studies have reported the ability enterococci to 


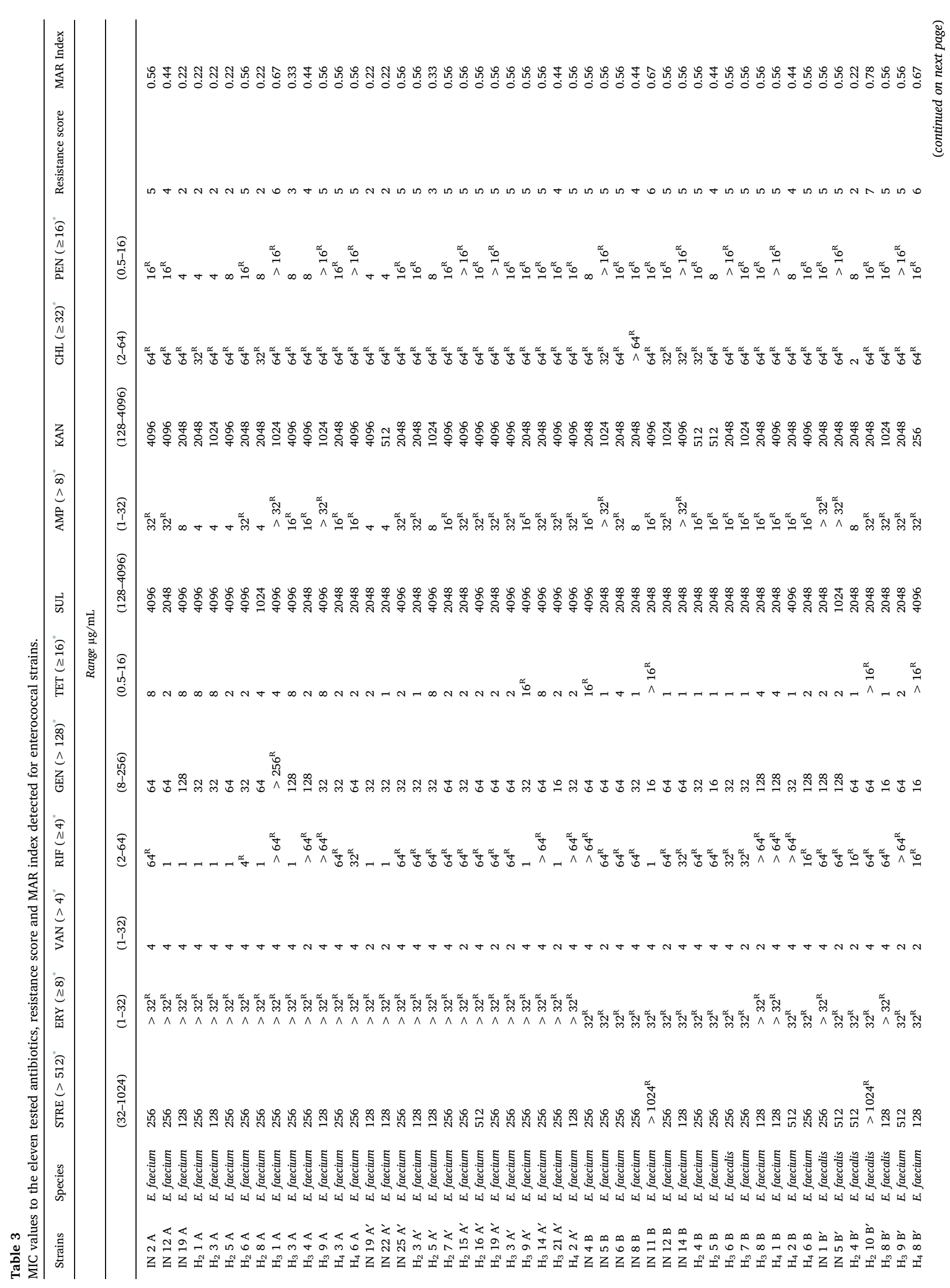




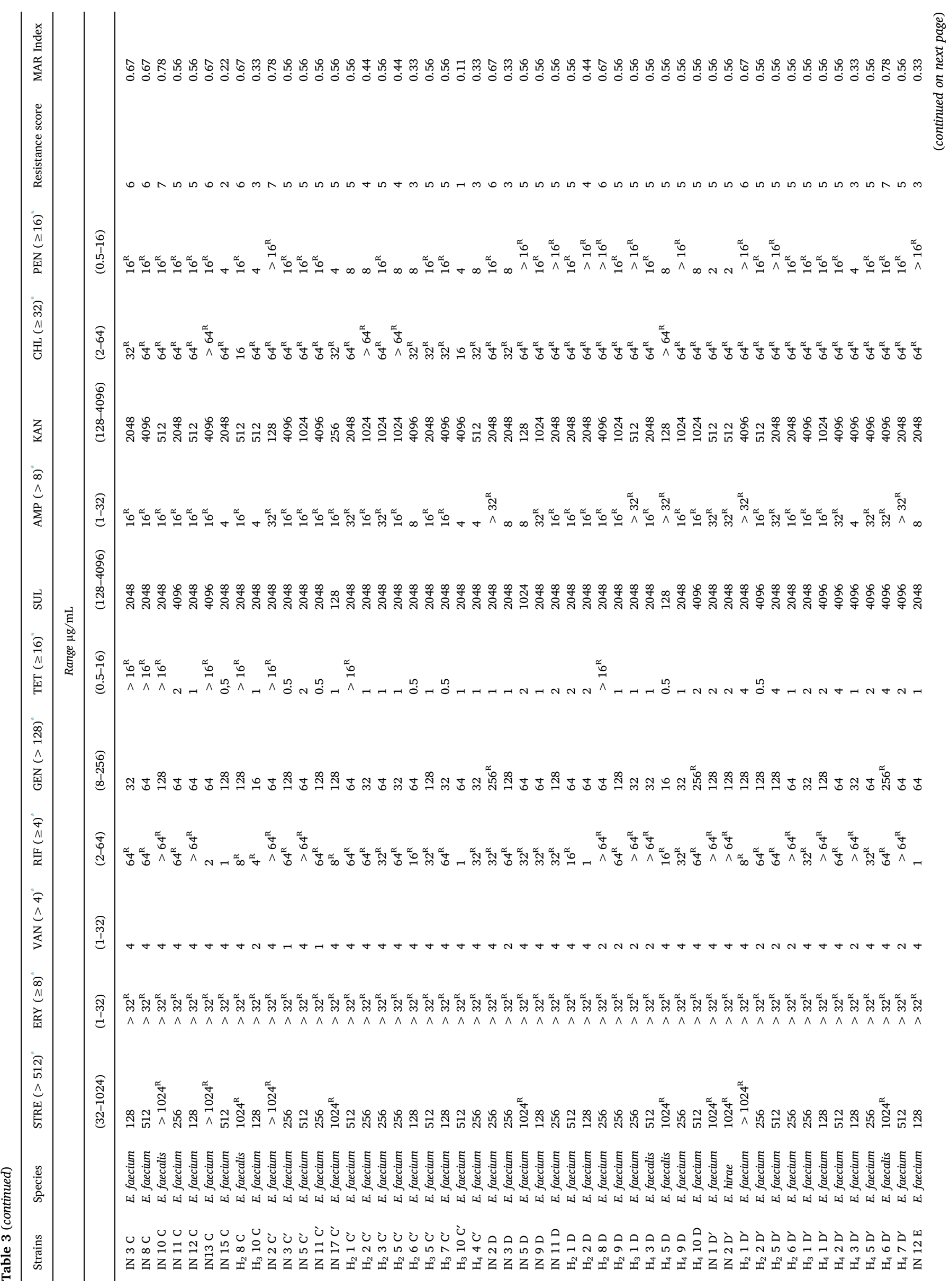




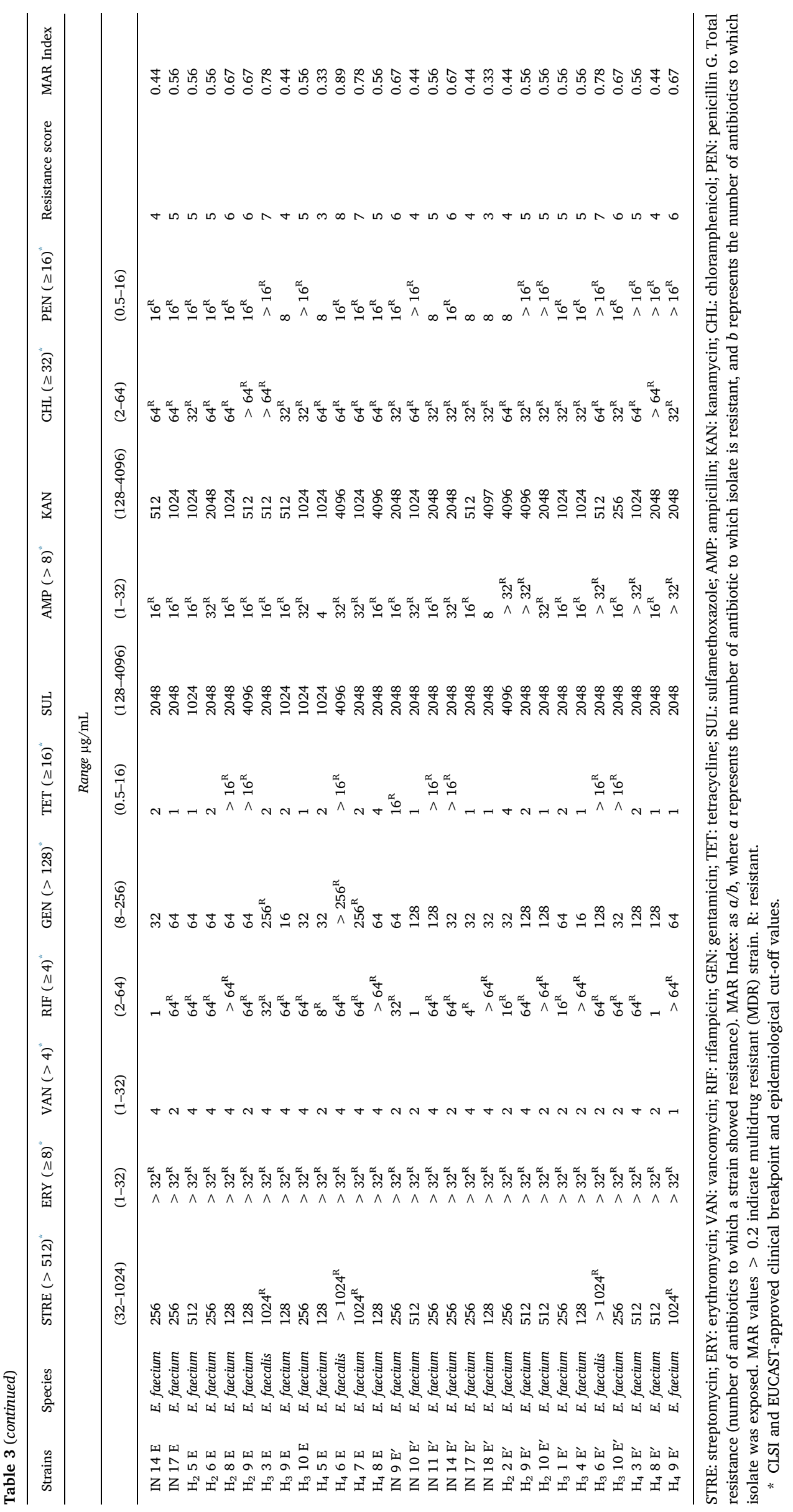


Table 4

Frequency of antibiotic resistant enterococci and Multiple Antibiotic Resistance (MAR) index at different sites.

\begin{tabular}{lllll}
\hline Site & $\begin{array}{l}\text { Number of } \\
\text { isolates }\end{array}$ & $\begin{array}{l}\text { Frequency (\%) of } \\
\text { MDR isolates }\end{array}$ & $\begin{array}{l}\text { MAR }^{*} \text { index } \\
\text { range of isolates }\end{array}$ & $\begin{array}{l}\text { MAR }^{\text {*** }} \\
\text { index of } \\
\text { site }\end{array}$ \\
\hline CWs Influent & 43 & $91 \%$ & $0.22-0.78$ & 0.52 \\
CW1 Effluent & 36 & $86 \%$ & $0.22-0.78$ & 0.50 \\
CW2 Effluent & 26 & $96 \%$ & $0.11-0.78$ & 0.53 \\
CW3 Effluent & 25 & $100 \%$ & $0.33-0.89$ & 0.51 \\
\hline
\end{tabular}

* MAR of strain is calculated as $=a / b$, where $a$ represents the number of antibiotic to which isolate is resistant, and $b$ represents the number of antibiotics to which isolate has been exposed. MAR values $>0.2$ indicate multidrug resistant (MDR) strain.

$* *$ MAR index of site is calculated as $=c /(n \cdot b)$, where $c$ represents the total number of resistance scored; $\mathrm{n}=$ number of isolates from the site; $b$ represents the number of tested antibiotics. Site MAR values $\geq 0.2$ indicate a site with a high risk of potential contamination by MDR strains.

resist to harsh conditions and/or to produce biofilms (Giebultowicz et al., 2017; Mohamed and Huang, 2007; Vilanova et al., 2004). The different persistence rates detected in the present study suggests a different enterococcal selection process in the CW sites, as previously observed (Ferreira da Silva et al., 2006; Łuczkiewicz et al., 2010; Martins da Costa et al., 2006).

\subsection{Identification of enterococcal isolates}

MALDI-TOF MS was performed to characterize the 130 presumptive enterococcal isolates. For clustering analysis, quality of the MS spectra was evaluated and spectra were considered to be of good quality when characterized by a low ( $<30 \%$ of the maximal peak intensity) slope (i.e. high background in the lower $\mathrm{m} / \mathrm{z}$ range), a minimal number of peaks equal to five and a minimal highest peak intensity of 500. MS profiles were generated for the 130 isolates (data not shown). Overall, the highest prevalence was observed for E. faecium (88\%) and E. faecalis (11\%), the most common causative agents of nosocomial infections. It is interesting to observe that prevalence of E. faecium has been rarely reported on environmental sources and on domestic wastewater (Graves and Weaver, 2010). In detail, among the 43 strains isolated from inlet samples, $39(91 \%)$ were ascribed to $E$. faecium, $3(7 \%)$ to $E$. faecalis and $1(2 \%)$ to $E$. hirae. Among the 36 isolates from CW1 effluent, $33(92 \%)$ were ascribed to E. faecium and $3(8 \%)$ to E. faecalis. Among the 26 isolates from CW2 effluent, 22(85\%) were ascribed to $E$. faecium and $4(15 \%)$ to E. faecalis. Finally, among the 25 isolates from CW3 effluent, $21(84 \%)$ were ascribed to E. faecium and $4(16 \%)$ to $E$. faecalis species. The high persistence of $E$. faecalis in CW units could be ascribed to the ability of this species to adhere to zooplankton and to persist in the environment for extended period of time (Ferreira da Silva et al., 2006; Łuczkiewicz et al., 2010) while the high prevalence of $E$. faecium is in agreement with the increasing dominance of the species recently observed in environment samples in all around the world (Aarestrup et al., 2000).

\subsection{Phenotypic antibiotic resistance of enterococci}

Although comparing antibiotic resistances in environmental samples is very difficult, given the absence of any standardized methods, some trends could be outlined, at least within enterococcal population that represents the most investigated bacteria in UWTPs. Several authors, using distinct methodologies, indicated high resistance rates (20-44\%) for tetracycline, erythromycin and quinolones and considerably lower resistance for aminopenicillins and sulfonamides (1-7\%) (Ferreira da Silva et al., 2006; Łuczkiewicz et al., 2010; Martins da Costa et al., 2006). Results of the MIC value, expressed as $\mu \mathrm{g} / \mathrm{mL}$, of enterococcal strains here investigated, are reported in Table 3. It is relevant to point out that all of the 130 strains showed antibiotic resistance to erytromycin and susceptibility to vancomycin. This latest finding could be related to the distance (about $12 \mathrm{~km}$ ) of the considered plant to the nearest hospital, located in Caltagirone town, and is in agreement with recent observations on the low prevalence of VRE in WWTPs, confirming that the presence of VRE may vary depending on the sampling site and on treatment policies of various regions (Oravcova et al., 2017; Taucer-Kapteijn et al., 2016).

Considering total resistance, results highlighted the highest occurrence of resistance for choramphenicol (97\%), followed by rifampicin (84\%), ampicillin (83\%), and penicillin (73\%), and the lowest for gentamicin (5.4\%).

Comparing to E. faecium, E. faecalis strains showed higher prevalence of resistance against streptomycin ( $57 \%$ vs $8 \%)$, tetracycline (36\% vs $14 \%$ ) and gentamycin ( $21 \%$ vs $3 \%$ ). In addition, $93 \%$ of $E$. faecalis strains were found ampicillin resistant, even if this is considered as a rare trait in E. faecalis (EUCAST, 2018). Resistance to these antibiotics has been related to the frequent and continuous usage of penicillin and aminoglycosides, for empirical treatment of infectious disease (Aarestrup et al., 2000; Arvanitodou et al., 2001; Devarajan et al., 2015), and to the widespread prevalence of resistance genes in the environment (Jamet et al., 2012; Kang et al., 2017). The unique E. hirae strain, isolated from inlet, showed resistance to erythromycin, streptomycin, rifampicin, ampicillin and chloramphenicol. In addition, all enterococci were analyzed for the sulphametoxazole and kanamycin resistance, for which no breakpoints are available. For both the

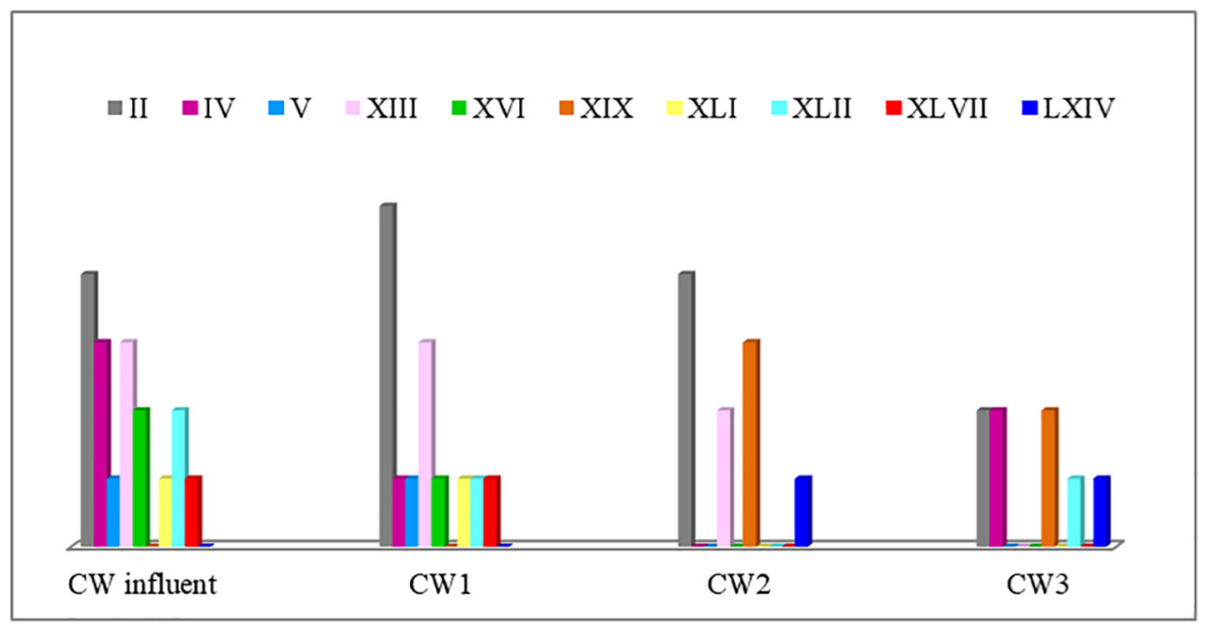

Fig. 1. Prevalence of most recurring pulso-types of E. faecium in CW influent and effluents. 


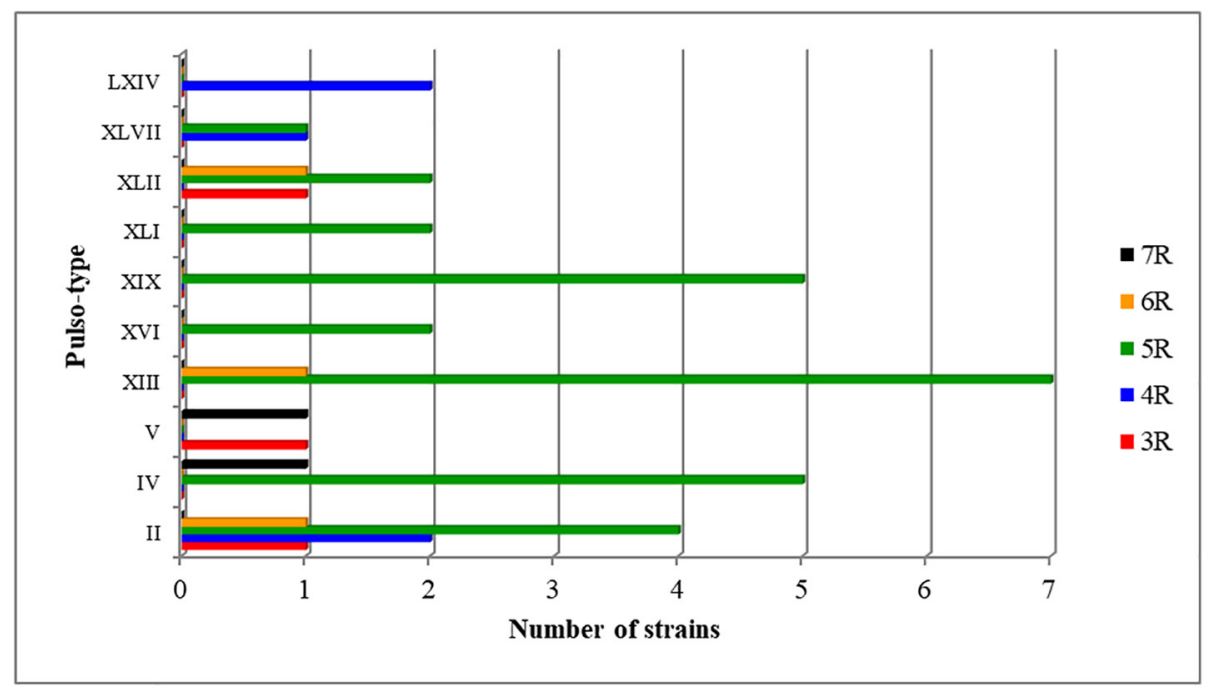

Fig. 2. Distribution of MDR (expressed as resistance from 3 to 7 antibiotics) among most recurring pulso-types within E. faecium population.

aforementioned antibiotics $27 \%$ of strains showed a MIC value of $4096 \mu \mathrm{g} / \mathrm{mL}$, which was the highest among the tested range.

Evaluating the multidrug resistance of strains, $70(54 \%)$ were resistant to 5 antibiotics, $16(12 \%)$ to 6 antibiotics, and 7(4\%) to 7 antibiotics. Furthermore, a high prevalence of MDR strains was detected in each sampling site. Considering the inlet, where the value of MDR isolates was $91 \%$, a decrease was observed only in CW1 site (Table 4). Considering the MAR index of each isolate, the highest value was 0.89 , for one $E$. faecalis strain isolated from CW3 effluent, whereas the lowest (0.11) was detected for one E. faecium strain, isolated from CW2 effluent, that showed resistance exsclusively to erythromycin (Table 3).

The MAR index for each sampling site was 0.52 for CWs influent and $0.50,0.53$ and 0.51 for CW1, CW2 and CW3 effluents, respectively. These values are higher than the arbitrary value of risk contamination and indicate the CWs as relevant risk contamination sites (Krumperman, 1983). Moreover no correlation was found between MAR index values of different sites with neither to the bacterial removal efficiency or system parameters. Although a reduced abundance of AR enterococci has been reported (Taučer-Kapteijn et al., 2016), in the present study MDR enterococci persisted in all three sampling sites, with the highest prevalence in CW3 effluents, where the highest number of $E$. faecalis strains was detected.

In the present study, a high prevalence of resistances was observed, revealing a given multidrug resistance, mainly against erythromycin, chloramphenicol, rifampicin and ampicillin. The concern for the high prevalence of MDR enterococci is alarming considering that bacteria with antibiotic resistance factors have a selective advantage over antibiotic sensitive forms in the natural environment.

Results of correlation analyses performed between strain resistance patterns and tested antibiotics revealed the clustering of enterococcal population into two large groups, highlighting a correlation among susceptibility to streptomycin, gentamicin and tetracycline. Whereas the resistance to ampicillin was correlated to resistance to penicillin, rifampicin and chloramphenicol (data not shown).

\subsection{Clonal relatedness}

The genotyping identification, established by SmaI PFGE, showed a high genetic diversity. Several pulso-types with a unique pattern were detected, demonstrating the independent origin of the strains. PFGE profiles of the 130 strains showed 15-20 fragments ranging from approximately 48.5 to $291 \mathrm{~kb}$ in size, differentiating the isolates in very numerous different patterns, with Dice's coefficient of similarity (CS) higher than 95\%. Among obtained pulso-types, over 40 PFGE patterns were unique, including strains isolated from different sampling points (data not shown). The high diversity could be attributed to the reiterate exposure to environmental stresses that may have promoted evolutionary processes, such as mutation, selection and recombination, necessary for the adaptation of enterococcal population. Within the ten clonal groups, which included strains with comparable PFGE profiles, a certain pulso-type recurrence was observed in the different $\mathrm{CW}$ effluents (Fig. 1). In details, CW1 site showed a clone occurrence very similar to those detected into inlet site, whereas CW2 and CW3 sites showed a different pulso-type arrangement, with the dominance of clones not detected in influent (Fig. 1). In addition, different patterns of resistance were detected among the same E. faecium pulso-types (Fig. 2). In particular, within the ten most recurrent clone groups, six pulso-types exhibited different phenotypic resistance patterns, being resistant to a different number of antibiotics (Fig. 2) and to different specific antibiotic molecules (data not shown).

Regarding the MIC rate, a different MIC value distribution was observed between CW influent and effluents. In details, as reported in Fig. 3, among E. faecium strains, in all CW effluents, an increase of MIC values for rifampicin and for sulphametoxazole, and conversely a general decrease for tetracycline was registered.

Overall, a higher variability was detected among $E$. faecalis strains with a remarkable different trend among CW effluents. In particular, higher MIC values were detected for streptomycin and lower values for rifampicin, in all CW effluents. In addition, higher MIC values for both vancomycin and gentamycin were found in CW2 and CW3 effluents, whereas decreased values were registered for ampicillin in CW1 and CW2, and for penicillin in CW1 and CW3 effluents (Fig. 3).

In the present study the persistence of the same E. faecium pulsotypes in both different sites and sampling periods, suggests the common presence of some peculiar clone in the ecosystem. Within the same pulso-type, different phenotypic resistance patterns were observed, confirming the high-level of plasticity of the enterococcal genome and the role of the system in the dissemination of resistance (Rizzo et al., 2013). Overall, the evidences on dissemination of clinically relevant antimicrobial resistance traits among enterococci in non-hospital environments supports the concept of exogenous acquisition of resistant determinants, creating an additional need to understand the fate of AR enterococci. Although the irrigation with reclaimed wastewater has been widely applied in different countries to mitigate the water shortage, the current state of knowledge alerts about AR enterococci, which are not completely eliminate by the most conventional wastewater treatment processes and for which neither Italian nor European legislation provides any limit. 


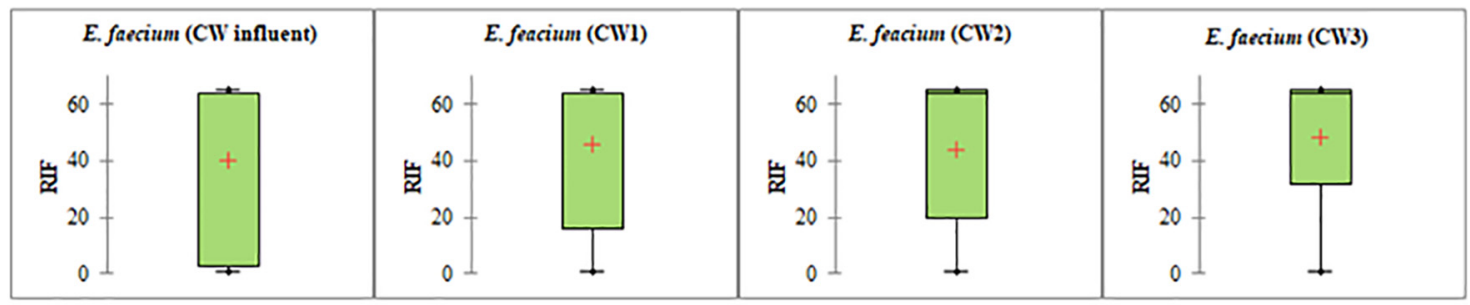

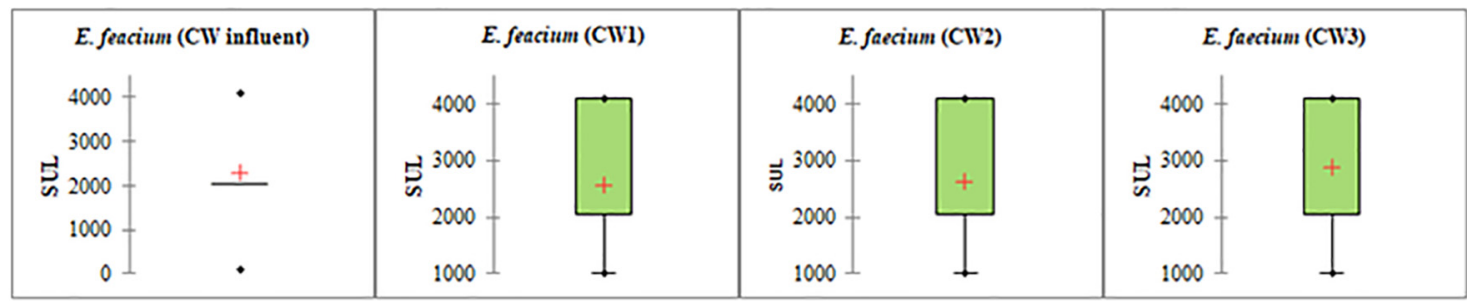

\begin{tabular}{|c|c|c|c|}
\hline E. faecium (CW influent) & \multicolumn{1}{|c|}{ E. faecium (CW1) } & E. faecium (CW2) & E. faecium (CWu) \\
\hline
\end{tabular}

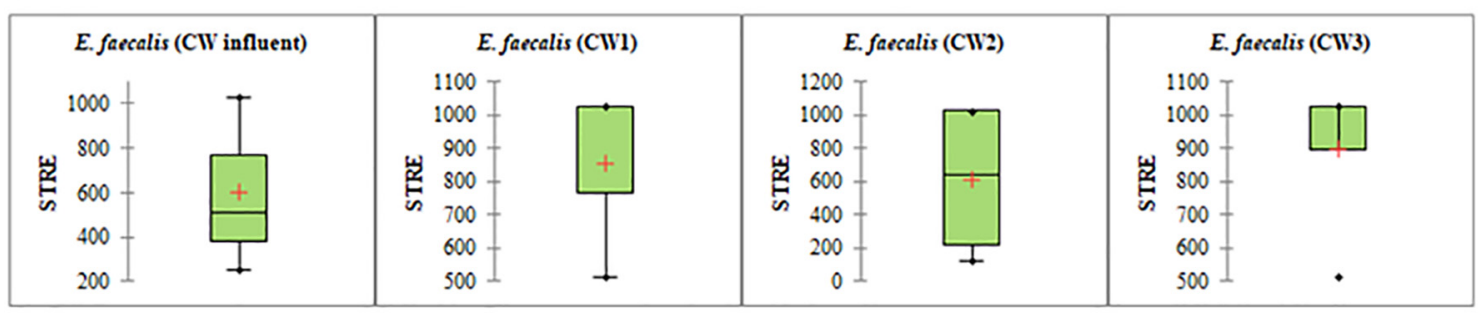

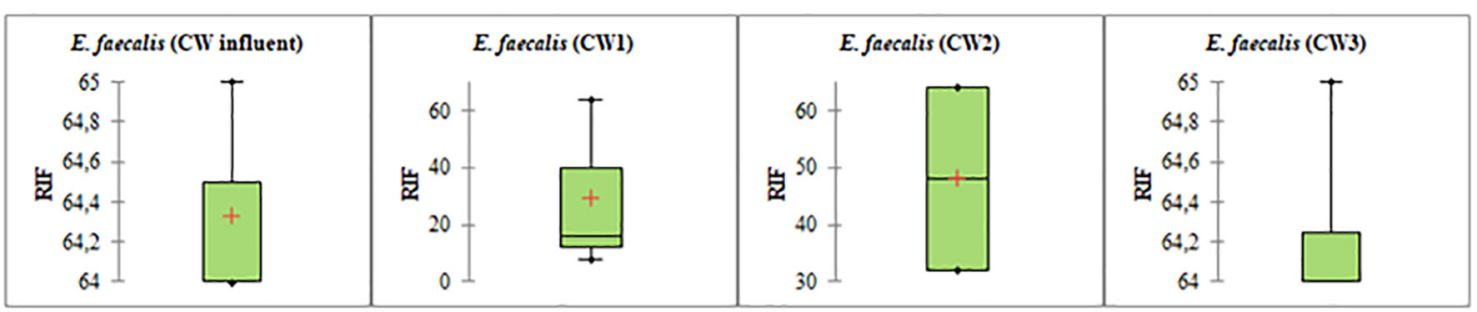
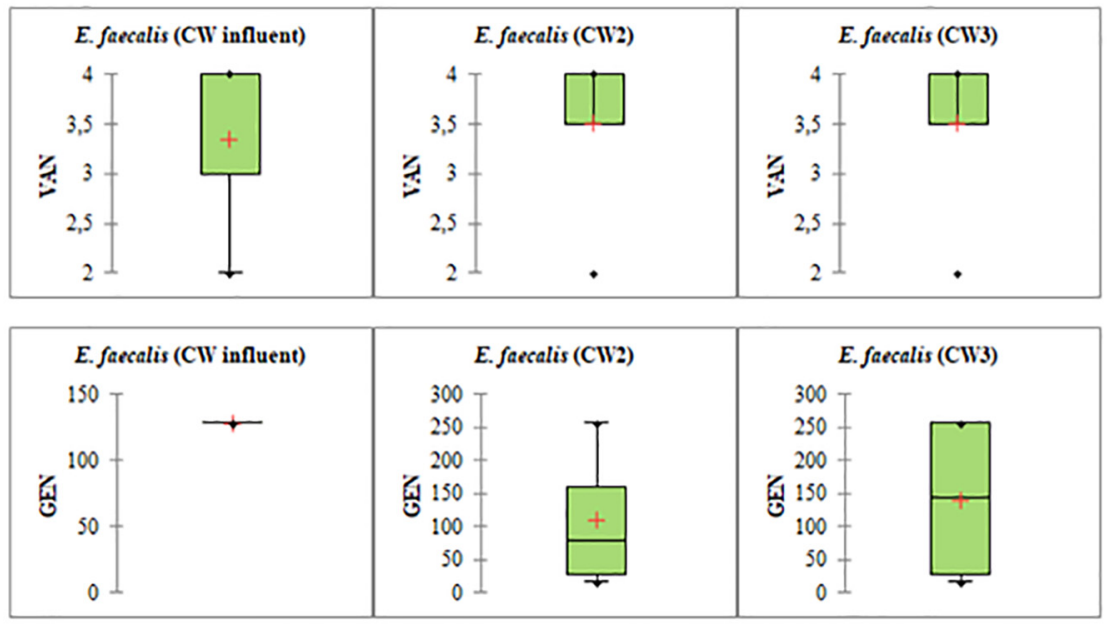

Fig. 3. Box-plot of MIC values distribution among strains in CW inflent and effluents. 

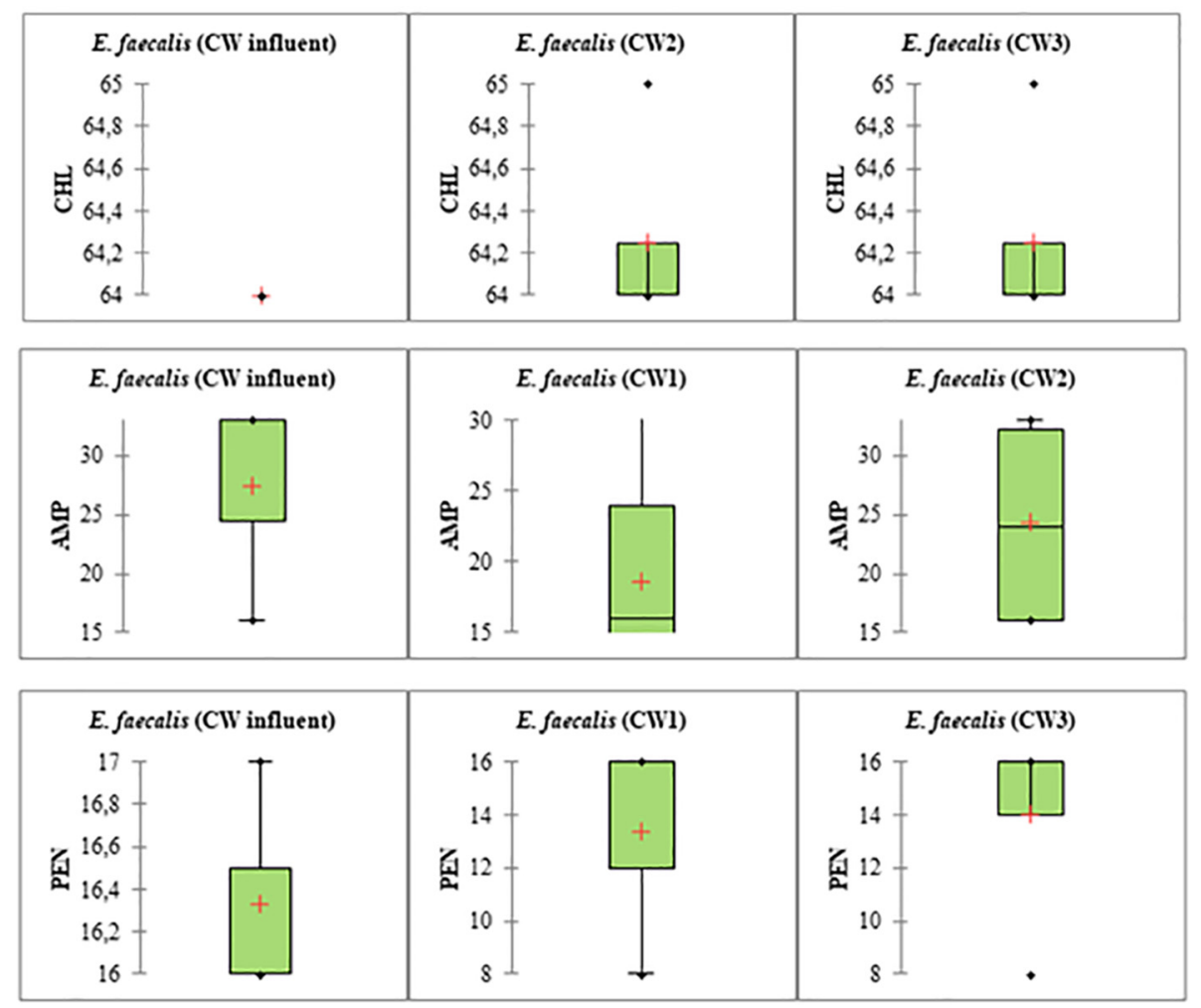

Fig. 3. (continued)

\section{Conclusions}

The persistence of AR enterococci in UWTPs suggests their possible spreading to both surface waters and vegetables crops through irrigation, and could contribute to increase the risk of AR transmission via food chain. Although the CWs show different effects, the high prevalence of antibiotic resistance prompts a selective advantage in such a natural environment and the high MAR index in all sampling sites represents an alarming public health risk. In order to preserve the water quality of the receiving systems, the optimization of wastewater treatment parameters and the implementation of further technologies together with a strict management strategy are urgently required.

\section{Acknowledgments}

This work was carried out within the WATER4CROPS EU FP7 Project - Integrating biotreated wastewater reuse and valorization with enhanced water use efficiency to support the Green Economy in EU and India, financed by EU (FP7 grant No. 311933).

Nunziatina Russo internship was funded by SIMTREA at DeFENS, University of Milan, and by University of Catania as PhD student.

\section{References}

Aarestrup, F.M., Agerso, Y., Gerner-Smidt, P., Madsen, M., Jensen, L.B., 2000 Comparison of antimicrobial resistance phenotypes and resistance genes in Enterococcus faecalis and Enterococcus faecium from humans in the community, broilers, and pigs in Denmark. Diagnostic. Microbiol. Inf. Dis. 37, 127-137.

Arvanitidou, M., Katsouyannopoulos, V., Tsakris, A., 2001. Antibiotic resistance patterns of enterococci isolated from coastal bathing waters. I. J. Med. Microbiol. 50, 1001-1005.

APHA, American Public Health Association, 2006. Standard Methods for the Examination of Water. American Public Health Association, New York.

Barbagallo, S., Cirelli, G.L., Marzo, A., Milani, M., Toscano, A., 2011. Hydraulic behaviour and removal efficiencies of two H-SSF constructed wetlands for wastewater reuse with different operational life. Water Sci. Technol. 64, 1032-1039.

Byappanahalli, M.N., Nevers, M.B., Korajkic, A., Staley, Z.R., Harwood, V.J., 2012. Enterococci in the environment. Microbiol. Mol. Biol. Rev. 76, 685-706.

Cirelli, G.L., Consoli, S., Di Grande, V., Milani, M., Toscano, A., 2007. Subsurface constructed wetlands for wastewater treatment and reuse in agriculture: five years of experiences in Sicily. Italy. Water Sci. Technol. 56, 183-191.

CLSI, Clinical and Laboratory Standards Institute, 2016. Performance Standards for Antimicrobial Susceptibility Testing, 26th Edition CLSI supplement M100S. CLSI, Wayne, PA, USA.

Devarajan, N., Laffite, A., Graham, N.D., Meijer, M., Prabakar, K., Mubedi, J.I., Elongo, V., Mpiana, P.T., Ibelings, B.W., Wildi, W., Poté, J., 2015. Accumulation of clinically relevant antibiotic-resistance genes, bacterial load, and metals in freshwater lake sediments in Central Europe. Environ. Sci. Technol. 49, 6528-6537.

Doan, N.T.L., Van Hoorde, K., Cnockaert, M., De Brandt, E., Aerts, M., Le Thanh, B. Vandamme, P., 2012. Validation of MALDI-TOF MS for rapid classification and identification of lactic acid bacteria, with a focus on isolates from traditional fermented foods in Northern Vietnam. Lett. Appl. Microbiol. 55, 265-273.

EUCAST, European Committee on Antimicrobial Susceptibility Testing EUCAST. Breakpoint tables for interpretation of MICs and zone diameters. Version 8.1. 2018. http://www.eucast.org.

Ferreira da Silva, M., Tiago, I., Veríssimo, A., Boaventura, R.A., Nunes, O.C., Manaia, C.M., 2006. Antibiotic resistance of enterococci and related bacteria in an urban wastewater treatment plant. FEMS Microbiol. Ecol. 55, 322-329.

Gao, W., Howden, B.P., Stinear, T.P., 2018. Evolution of virulence in Enterococcus faecium, a hospital-adapted opportunistic pathogen. Curr. Opinion Microbiol. 41, 76-82.

Giebułtowicz, J., Tyski, S., Wolinowska, R., Grzybowska, W., Zaręba, T., Drobniewska, A., Wroczyński, P., Nałęcz-Jawecki, G., 2017. Occurrence of antimicrobial agents, drugresistant bacteria, and genes in the sewage-impacted Vistula River (Poland). Environ. Sci. Pollut. Res. 25, 5788-5807.

Graves, A.K., Weaver, R.W., 2010. Characterization of enterococci populations collected from a subsurface flow constructed wetland. J. Appl. Microbiol. 108, 1226-1234.

Hay, S.I., Rao, P.C., Dolecek, C., Day, N.P.J., Stergachis, A., Lopez, A.D., Murray, C.J.L., 2018. Measuring and mapping the global burden of antimicrobial resistance. BMC Medicine 16, 78 .

Jamet, E., Akary, E., Poisson, M.A., Chamba, J.F., Bertrand, X., Serror, P., 2012 Prevalence and characterization of antibiotic resistant Enterococcus faecalis in French cheeses. Food Microbiol. 31, 191-198.

Kang, B., Kim, D.H., Chon, J.W., Seo, K.H., 2017. Effect of microbial control measures on farmstead cheese-making and antimicrobial resistance of Staphylococcus aureus and Enterococcus spp. isolates. J. Food Saf., e12432.

Kim, S., Jensen, J.N., Aga, D.S., Weber, A.S., 2007. Tetracycline as a selector for resistant bacteria in activated sludge. Chemosphere 66, 1643-1651.

Krumperman, P.H., 1983. Multiple antibiotic resistance indexing of Escherichia coli to identify high-risk sources of fecal contamination of foods. Appl. Environ. Microbiol. 46, 165-170.

Lavrnic, S., Braschi, I., Anconelli, S., Blasioli, S., Solimando, D., Mannini, P., Toscano, A., 2018. Long-term monitoring of a surface flow constructed wetland treating agricultural drainage water in Northern Italy. Water 10, 1-16.

Luczkiewicz, A., Fudala-Ksiazek, S., Jankowska, K., Quant, B., Olańczuk-Neyman, K., 2010. Diversity of fecal coliforms and their antimicrobial resistance patterns in 
wastewater treatment model plant. Water Sci. Technol. 61, 1383-1392.

Martínez, J.L., Baquero, F., 2014. Emergence and spread of antibiotic resistance: setting a parameter space. Upsala J. Med. Sci. 119, 68-77.

Martins da Costa, P., Vaz-Pires, P., Bernardo, F., 2006. Antimicrobial resistance in Enterococcus spp. isolated in inflow, effluent and sludge from municipal sewage water treatment plants. Water Res. 40, 1735-1740.

Mohamed, J.A., Huang, D.B., 2007. Biofilm formation by enterococci. J. Med. Microbiol. $56,1581-1588$.

Novais, C., Coque, T.M., Sousa, J.C., Baquero, F., Peixe, L., et al., 2004. Local genetic patterns within a vancomycin-resistant Enterococcus faecalis clone isolated in three hospitals in Portugal. Antimicrob. Agents Chemother. 48, 3613-3617.

Oravcova, V., Mihalcin, M., Zakova, J., Pospisilova, L., Masarikova, M., Literak, I., 2017. Vancomycin-resistant enterococci with vanA gene in treated municipal wastewater and their association with human hospital strains. Sci. Total Environ. 609, 633-643.

Rizzo, L., Manaia, C., Merlin, C., Schwartz, T., Dagot, C., Ploy, M.C., Michael, I., FattaKassinos, D., 2013. Urban wastewater treatment plants as hotspots for antibiotic resistant bacteria and genes spread into the environment: a review. Sci. Total Environ. 447, 345-360.

Rodriguez-Mozaz, S., Chamorro, S., Marti, E., Huerta, B., Gros, M., Sanchez- Melsiò, A., Borrego, C.M., Barcelò, D., Balcazar, J.L., 2015. Occurrence of antibiotics and antibiotic resistance genes in hospital and urban wastewaters and their impact on the receiving river. Water Res. 69, 234-242.
Russo, N., Caggia, C., Pino, A., Coque, M.T., Arioli, S., Randazzo, C.L., 2018. Enterococcus spp. in Ragusano PDO and Pecorino Siciliano cheese types: a snapshot of their antibiotic resistance distribution. Food Chem. Toxicol. 120, 277-286.

Taučer-Kapteijn, M., Hoogenboezem, W., Heiliegers, L., de Bolster, D., Medema, G., 2016. Screening municipal wastewater effluent and surface water used for drinking water production for the presence of ampicillin and vancomycin resistant enterococci. Int. J. Hyg. Environ. Health 219, 437-442.

Tenover, F.C., Arbeit, R.D., Goering, R.V., Mickelson, P.A., Murray, B.E., Persing, D.H., 1995. Interpreting chromosomal DNA restriction patterns produced by pulsed-field gel electrophoresis: criteria for bacterial strain typing. J. Clin. Microbiol. 33, 2233-2239.

Vilanova, X., Manero, A., Cerdà-Cuéllar, M., Blanch, A.R., 2004. The composition and persistence of faecal coliforms and enterococcal populations in sewage treatment plants. J. Appl. Microbiol. 96, 279-388.

Werner, G., Coque, T.M., Franz, C.M., Grohmann, E., Hegstad, K., van Schaik, W., Weaver, K., 2013. Antibiotic resistant enterococci-tales of a drug resistance gene trafficker. Int. J. Med. Microbiol. 303, 360-379.

WHO, World Health Organization, 2017. Global Priority List of Antibiotic-Resistant Bacteria to Guide Research, Discovery, and Development of New Antibiotics. http:// www.who.int/medicines/publications/global-priority-list-antibioticresistantbacteria/en/. 